\title{
The Effect of Storage Time, Temperature and Type of Packaging on the Release of Phthalate Esters into Packed Acidic Liquids
}

\author{
Noushin Rastkari ${ }^{1,2 *}$, Maryam Zare Jeddi ${ }^{2}$, Masud Yunesian ${ }^{3}$ and Reza Ahmadkhaniha ${ }^{4}$ \\ ${ }^{1}$ Center for Water Quality Research, Institute for Environmental Research, Tehran University of Medical \\ Sciences, Tehran, Iran \\ ${ }^{2}$ Center for Air Pollution Research, Institute for Environmental Research, Tehran University of Medical Sciences, \\ Tehran, Iran \\ ${ }^{3}$ Department of Environmental Health Engineering, School of Public Health, \\ Tehran University of Medical Sciences, Tehran, Iran \\ ${ }^{4}$ Department of Human Ecology, School of Public Health, Tehran University of Medical Sciences, Tehran, Iran \\ Received: December 26, 2016 \\ Accepted: August 25, 2017
}

\begin{abstract}
Summary
Acidic liquids such as verjuice, lemon juice and vinegar are frequently consumed in Iran. Different kinds of acidic liquids are packaged in polyethylene terephthalate (PET) and high-density polyethylene (HDPE) bottles. There is evidence indicating that phthalates can leach from PET and HDPE bottles into their contents. In this work the effect of storage time, temperature and bottle type on the migration of phthalates from packaging materials into acidic liquids is studied by analyzing the samples stored under different conditions, before storage and after 2, 4 and 6 months of storage. The determined mean phthalate concentrations in $\mu \mathrm{g} / \mathrm{L}$ were: $<0.04$ to 0.501 in verjuice, $<0.04$ to 0.231 in lemon juice and $<0.04$ to 0.586 in vinegar. The highest concentrations of diethyl phthalate (DEP) and diethyl hexyl phthalate (DEHP) were found in PET and HDPE bottles, respectively. Results of analyses before and after storage indicate that under some storage conditions, the concentrations of DEP, DEHP and dibutyl phthalate (DBP) increased in acidic liquids. The possible migration of phthalic acid esters from plastic packaging materials into the contents was indicated by the results of the present study.
\end{abstract}

Key words: phthalate esters, migration, storage condition, polyethylene terephthalate (PET), high-density polyethylene (HDPE)

\section{Introduction}

In recent years, due to the rise in industrialization and civilization, increased request for application of plastic packaging materials has been observed. Today, more than 30 types of plastic materials are utilized in the food industries, where polyethylene terephthalate (PET) and high-density polyethylene (HDPE) are among the most frequently used ones (1). Polyethylene terephthalate is a thermoplastic polymer with long branches belonging to polyester family, made by blending and polymerization between monoethylene glycol and dimethyl terephthalate or terephthalic acid (2). Despite their advantages, such as low volume and mass, high flexibility, desirable transparency, low permeability, gas tightness, and easy transportation, there are concerns about their use due to the probability of presence and liberation of harmful chemical compounds from packaging materials. Previous experiments showed that some of the harmful chemical compounds including phthalates can leach from

"Corresponding author: Phone: +98 2188978 395; Fax: +98 2188978 398; E-mail: nr_rastkari@yahoo.com 
packaging materials under certain conditions (2-4). Phthalate esters enter the human body through various means including dermal absorption, inhalation and ingestion, where the highest exposure takes place through ingestion of contaminated food (4). It is also found that one of the main reasons for food contamination can be food packaging (5-7). Most of the phthalate esters belong to the endocrine and metabolic disruptors (8-10), the long-term exposure to which can result in different types of adverse effects, disorders and cancers including breast cancer, prostate cancer (8), disorders of androgenic hormone biosynthesis and function (11), thyroid gland disorders $(12,13)$, infertility $(14)$, attention deficit hyperactivity disorder (ADHD) (15), obesity, liver damage, proliferation of free radicals, allergic reactions, asthma, mutagenicity and teratogenicity (16). Responsible governmental agencies in Canada, the EU, Australia and the USA have banned or restricted the use of phthalates in consumer products (17). It is a reason why detection of phthalates in packaged food has attracted great attention. Cirillo et al. (18) studied the influence of temperature and preservation time on migration of diethyl hexyl phthalate from PET packaging into packed meal. In another study, the concentration of phthalate esters in bottled water was determined within the $\mathrm{pH}=5-9$ after 140 days of preservation under different conditions (19). As in many other industrialized countries, packed foods are very common in Iran, which has raised concern about population health since 1990. Verjuice, lemon juice and vinegar, whose acidic condition can accelerate chemical degradation reactions, packed in plastic bottles are among highly consumed foods in Iran. Therefore, since our literature review revealed that so far no study has been carried out to determine the probability of phthalate ester migration from packaging materials into acidic foods, in this study, migration of phthalate esters from PET and HDPE bottles into acidic liquids under different conditions is studied.

\section{Materials and Methods}

\section{Reagents and chemicals}

Polyethylene terephthalate (PET) and high-density polyethylene (HDPE) bottles were obtained from Iran Petrochemical Co. (Tehran, Iran). A standard solution of phthalate esters, containing six compounds dissolved in $n$ -hexane, including bis(2-ethylhexyl) phthalate (DEHP), di- $n$ octyl phthalate (DNOP), butyl benzyl phthalate (BBP), dibutyl phthalate (DBP), diethyl phthalate (DEP) and dimethyl phthalate (DMP) $(2.0 \mathrm{mg} / \mathrm{mL}, 99.8 \%$ purity), was obtained from Sigma-Aldrich (St. Louis, MO, USA). All the other chemicals and solvents were of analytical reagent grade or better and obtained from Merck (Darmstadt, Germany). Standards of phthalates were dissolved in methanol $(100 \mu \mathrm{g} /$ $\mathrm{mL}$ ) and used for preparing calibration and quality control working solutions. To reduce random error, benzyl benzoate (internal standard) was added to all of the samples $(1 \mu \mathrm{g} / \mathrm{L})$. A mixture of acetonitrile, water and isopropanol (40:20:40, by volume) was used as extraction solution. All the working and stock solutions were kept in the dark at $4{ }^{\circ} \mathrm{C}$ until analysis. The magnetic particles of poly(dimethylsiloxane) hydroxylated multiwall carbon nanotubes (PDMS/MWCNTs-OH) were prepared based on previous work (20). HPLC quality water was obtained with a Milli-Q system from Millipore Corporation (Bedford, MA, USA).

\section{Preparation of samples}

Fresh sour grape and lemon samples were purchased during harvest period at the main fruit and vegetable market in Tehran, Iran. After washing and drying, their juice was extracted by using an industrial juicer (model Ruby 2000 MKIII; Nutrifaster Inc., Seattle, WA, USA) and transferred to the laboratory in glass containers. The bulk pure vinegar sample was also purchased from a local producer before packaging. At the time of arrival, the initial concentrations of phthalate esters in bulk samples of liquids were measured as described below (samples at $t=0$ were used as control). Thereafter, the bulk samples were divided and poured into PET and HDPE bottles, and stored under different thermal conditions for different storage times: at 4-6, 25 and $50{ }^{\circ} \mathrm{C}$ for 2, 4 and 6 months, respectively.

\section{Extraction and measurement of phthalate esters}

The possibility of phthalate contamination during sample preparation and analysis was minimized by analyzing chemicals and solvents for contamination before use, cleaning the glassware, and subtracting the average concentrations of phthalate in the blank sample (if present) from the estimated values. Determination of the concentration of target compounds was carried out by using solid phase microextraction technique and GC-MS as described previously (20). For all the target compounds including DMP, DEP, DBP, BBP, DNOP and DEHP calibration curves were constructed at five concentrations $(0.02,0.1,0.5,1$ and $5 \mu \mathrm{g} / \mathrm{L})$ by using standard solutions of each of the phthalate esters (three replicates). In order to extract the analytes, magnetic PDMS/MWCNTs$-\mathrm{OH}$ nanoparticles $(10 \mathrm{mg})$ were weighed and washed with methanol and deionized water in sequence. Then, the conditioned magnetic particles and $\mathrm{NaCl}(1 \mathrm{~g})$ were added to 10 $\mathrm{mL}$ of each sample. The mixture was then shaken for $5 \mathrm{~min}$. An external magnet was used to gather the magnetic adsorbent to the side of the vial (within approx. $80 \mathrm{~s}$ ). After that, the supernatant was discarded, extraction solution $(2 \mathrm{~mL})$ was added and vortexed ( $3 \mathrm{~min}$ ) to elute phthalates from the sorbent. The magnetic sorbent was gathered to the side of the vial and the extraction solvent was evaporated at $37^{\circ} \mathrm{C}$ under nitrogen stream. The residue was reconstituted in methanol $(100 \mu \mathrm{L})$ for the subsequent GC-MS analysis. Gas chromatograph (Agilent 6890; Agilent Technologies, Palo Alto, CA, USA) equipped with a single quadruple mass spectrometer (Agilent 5973; Agilent Technologies) was used for GC-MS analysis. The gas chromatograph was fitted with an Agilent J\&W DB-5 ms column (30 m×0.25 mm i.d. $\times 0.25 \mu \mathrm{m}$ film thickness; Agilent Technologies). The GC ovens were programmed as follows: injector temperature was set at $290{ }^{\circ} \mathrm{C}$, the initial column temperature was set at $50^{\circ} \mathrm{C}$ and held for 1 min, first ramp: from 50 to $280{ }^{\circ} \mathrm{C}$ at a rate of $30^{\circ} \mathrm{C} / \mathrm{min}$, then to $310{ }^{\circ} \mathrm{C}$ at a rate of $15^{\circ} \mathrm{C} / \mathrm{min}$. The oven temperature was held at $310{ }^{\circ} \mathrm{C}$ for $4 \mathrm{~min}$. The sample was analyzed using splitless injection. The temperature of the transfer line was kept constant at $310{ }^{\circ} \mathrm{C}$. Helium (99.9999 \%) was used as a carrier gas at $1 \mathrm{~mL} / \mathrm{min}$ (constant flow). The mass spectrometer was operated in electron ionization (EI) mode, using selected ion monitoring (SIM) (20). 


\section{Quantification of phthalate esters}

The linearity of the calibration curves was assessed in the concentration range of $0.01-10 \mu \mathrm{g} / \mathrm{L}$. For all the analytes the correlation coefficients were determined in the range from 0.993 to 0.997 . The limits of detection (LODs) were estimated to be three times of the standard deviation of the baseline noise $(N=6)$. The limits of quantification (LOQs) were determined by the analysis of spiked samples. The lowest concentration of the analytes on the calibration curves with a precision of less than $20 \%$ coefficient of variation and an accuracy of $80-120 \%$ was considered as LOQ (20). Based on the results, the LODs and LOQs of the target analytes were in the range from 0.01 to 0.02 and 0.03 to $0.06 \mu \mathrm{g} / \mathrm{L}$, respectively.

\section{Statistical analysis}

In this work, SPSS v. 20.0 (21) was used for the analysis of the results. Mean values and standard deviations of determined concentrations are reported. Kolmogorov-Smirnov test was used to check the normality of concentrations in each group. Due to non-normal distribution of data, the nonparametric Kruskal-Wallis $\mathrm{H}$ test was applied to compare different storage conditions. The concentrations during the exposure periods were compared using the Friedman test. The differences were considered to be statistically significant whenever $\mathrm{p}$-value was lower than $5 \%(\mathrm{p}<0.05)$.

\section{Results and Discussion}

The mean phthalate concentrations in the samples were estimated to be within the range of $<0.04-0.501 \mu \mathrm{g} / \mathrm{L}$ in verjuice, $<0.04-0.231 \mu \mathrm{g} / \mathrm{L}$ in lemon juice and $<0.04-0.586 \mu \mathrm{g} / \mathrm{L}$ in vinegar. The assay of the initial concentrations of phthalate esters in bulk samples of juices indicated initial low concentrations of DEHP, DEP and DBP (close to the detection limits) in lemon juice and verjuice samples, while detectable levels of these compounds were found in vinegar sample (Table 1). DNOP, BBP and DMP were not found at detectable levels in any of the samples prior to or after storage. The average $\mathrm{pH}$ of lemon juice, verjuice and vinegar in this study was ranging from approx. 2.3 to 2.4, 2.5 to 2.7 and 2.7 to 2.8 , respectively. Based on the results of the present study, liquid type, bottle type, storage conditions and time are factors that may, to some extent, explain the release of phthalate esters from polymeric bottles into their contents. The effects of various conditions of storage on the release of phthalates, irrespective of exposure period, are summarized in Table 1. DEP and DEHP showed the highest level

Table 1. Concentrations of phthalates in acidic liquids under different storage conditions

\begin{tabular}{|c|c|c|c|c|c|}
\hline \multirow{2}{*}{ Bottle type } & \multirow{2}{*}{$t /$ storage $) /{ }^{\circ} \mathrm{C}$} & \multirow{2}{*}{ Acidic liquid } & \multicolumn{3}{|c|}{$\gamma /(\mu \mathrm{g} / \mathrm{L})$} \\
\hline & & & DEP & DBP & DEHP \\
\hline \multirow{12}{*}{ HDPE } & \multirow{3}{*}{ Control } & verjuice & $0.03 \pm 0.01$ & $<\mathrm{LOD}$ & $0.04 \pm 0.02$ \\
\hline & & lemon juice & $<$ LOD & $<\mathrm{LOD}$ & $<\mathrm{LOD}$ \\
\hline & & vinegar & $0.22 \pm 0.04$ & $0.11 \pm 0.02$ & $0.11 \pm 0.03$ \\
\hline & \multirow{3}{*}{4} & verjuice & $0.12 \pm 0.06$ & $0.11 \pm 0.06$ & $0.21 \pm 0.12$ \\
\hline & & lemon juice & $0.05 \pm 0.04$ & $0.07 \pm 0.04$ & $0.07 \pm 0.03$ \\
\hline & & vinegar & $0.26 \pm 0.04$ & $0.17 \pm 0.04$ & $0.34 \pm 0.09$ \\
\hline & \multirow{3}{*}{25} & verjuice & $0.25 \pm 0.15$ & $0.14 \pm 0.09$ & $0.30 \pm 0.18$ \\
\hline & & lemon juice & $0.09 \pm 0.05$ & $0.10 \pm 0.06$ & $0.12 \pm 0.07$ \\
\hline & & vinegar & $0.33 \pm 0.08$ & $0.21 \pm 0.07$ & $0.40 \pm 0.13$ \\
\hline & \multirow{3}{*}{50} & verjuice & $0.19 \pm 0.11$ & $0.11 \pm 0.07$ & $0.32 \pm 0.21$ \\
\hline & & lemon juice & $0.05 \pm 0.02$ & $0.07 \pm 0.05$ & $0.16 \pm 0.09$ \\
\hline & & vinegar & $0.27 \pm 0.04$ & $0.17 \pm 0.06$ & $0.43 \pm 0.16$ \\
\hline \multirow{12}{*}{ PET } & \multirow{3}{*}{ Control } & verjuice & $0.03 \pm 0.01$ & $<\mathrm{LOD}$ & $0.04 \pm 0.02$ \\
\hline & & lemon juice & $<\mathrm{LOD}$ & $<\mathrm{LOD}$ & $<\mathrm{LOD}$ \\
\hline & & vinegar & $0.22 \pm 0.04$ & $0.11 \pm 0.02$ & $0.11 \pm 0.03$ \\
\hline & \multirow{3}{*}{4} & verjuice & $0.15 \pm 0.08$ & $0.11 \pm 0.06$ & $0.11 \pm 0.06$ \\
\hline & & lemon juice & $0.07 \pm 0.04$ & $0.08 \pm 0.05$ & $0.07 \pm 0.04$ \\
\hline & & vinegar & $0.30 \pm 0.05$ & $0.16 \pm 0.03$ & $0.28 \pm 0.05$ \\
\hline & \multirow{3}{*}{25} & verjuice & $0.31 \pm 0.18$ & $0.14 \pm 0.08$ & $0.16 \pm 0.09$ \\
\hline & & lemon juice & $0.13 \pm 0.07$ & $0.11 \pm 0.07$ & $0.11 \pm 0.06$ \\
\hline & & vinegar & $0.40 \pm 0.13$ & $0.21 \pm 0.07$ & $0.35 \pm 0.09$ \\
\hline & \multirow{3}{*}{50} & verjuice & $0.22 \pm 0.13$ & $0.11 \pm 0.07$ & $0.20 \pm 0.12$ \\
\hline & & lemon juice & $0.07 \pm 0.04$ & $0.08 \pm 0.06$ & $0.11 \pm 0.06$ \\
\hline & & vinegar & $0.31 \pm 0.07$ & $0.19 \pm 0.06$ & $0.35 \pm 0.10$ \\
\hline
\end{tabular}

The results are expressed as mean values \pm standard deviations. $\mathrm{DEP}=$ diethyl phthalate, $\mathrm{DBP}=$ dibutyl phthalate, $\mathrm{DEHP}=$ bis $(2$-ethylhexyl $)$ phthalate, LOD=limit of detection, HDPE=high-density polyethylene, $\mathrm{PET}=$ polyethylene terephthalate 
of leaching into liquids packed in PET and HDPE bottles, respectively. The trend of change of DEHP concentration in all samples shows that the migration rate increased by increasing temperature. In the case of DEP and DBP, a negative trend was witnessed at $50{ }^{\circ} \mathrm{C}$ after a positive trend in concentration profiles at $25{ }^{\circ} \mathrm{C}$. The probable reason for this observation will be explained later in this section. Temperature had the greatest effect on the migration of DEHP. The maximum concentration of DEHP $(0.586 \mu \mathrm{g} / \mathrm{L}$, data not shown) was detected in vinegar packed in HDPE bottle
HDPE

a) $t=4{ }^{\circ} \mathrm{C}$

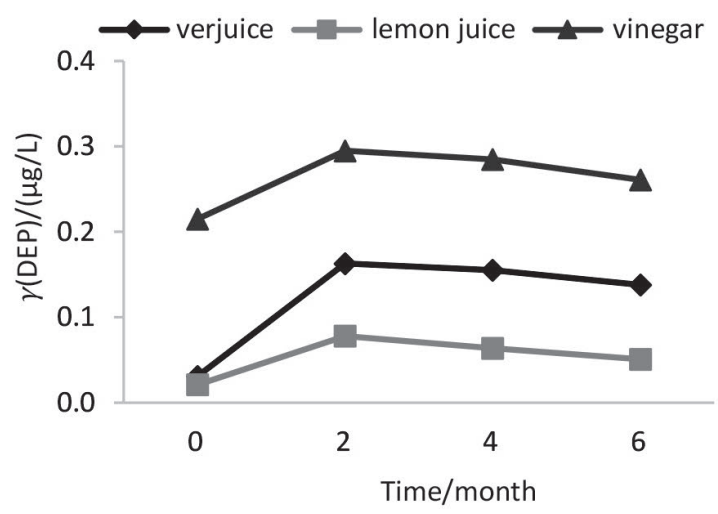

b) $t=25^{\circ} \mathrm{C}$

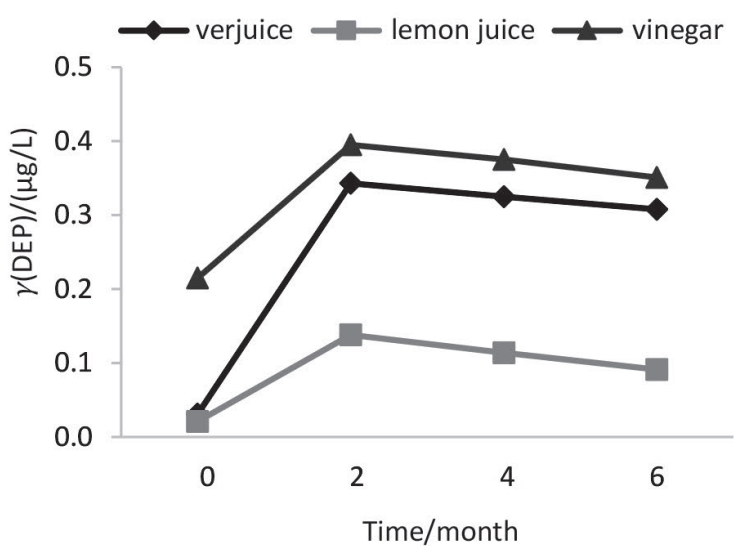

c) $t=50^{\circ} \mathrm{C}$

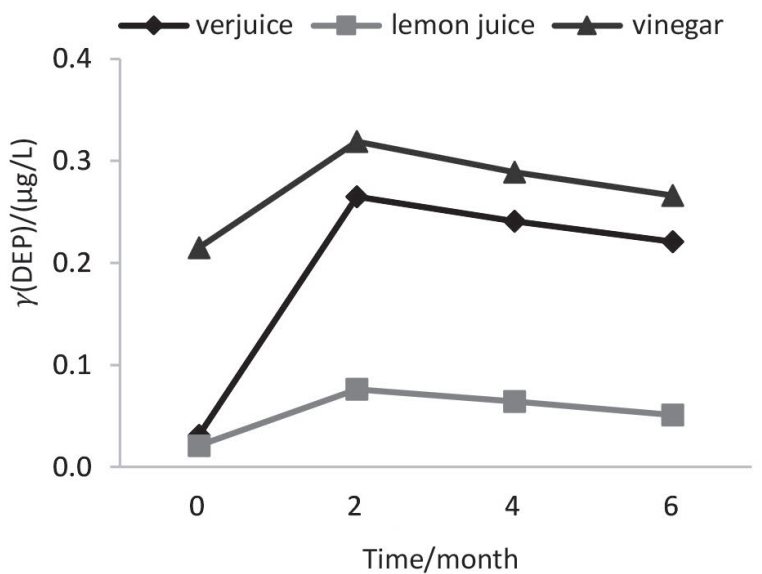

PET

d) $t=4{ }^{\circ} \mathrm{C}$

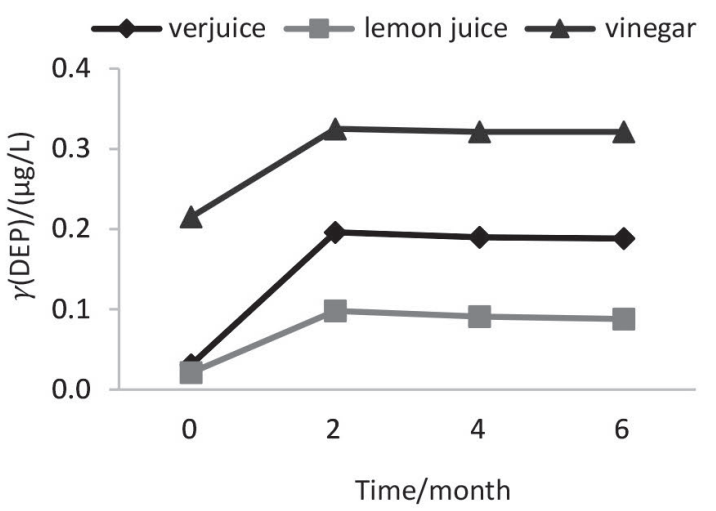

e) $t=25^{\circ} \mathrm{C}$

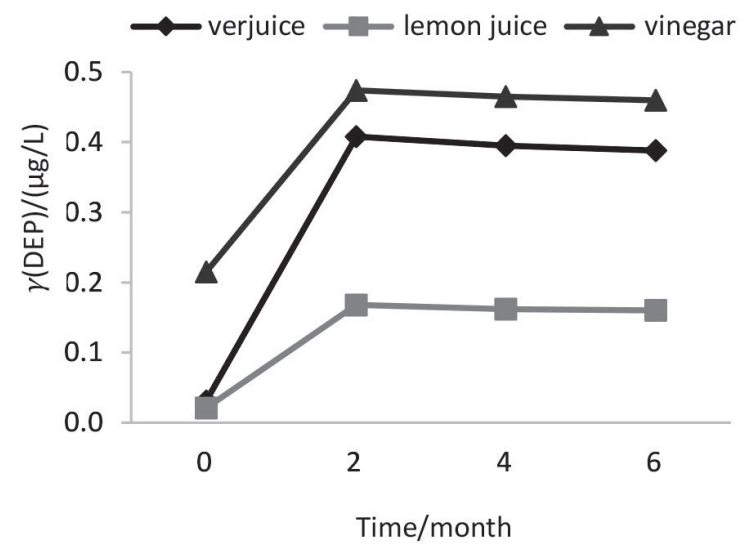

f) $t=50^{\circ} \mathrm{C}$

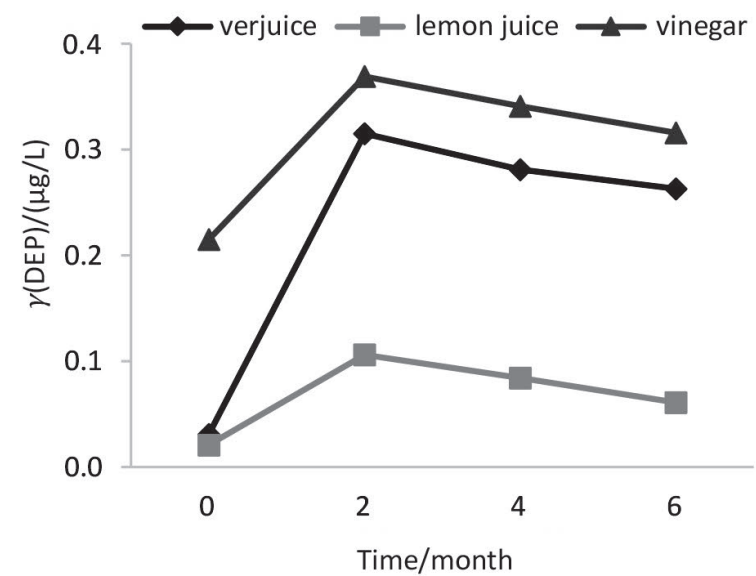

Fig. 1. The effect of time (0, 2, 4 and 6 months) under different storage conditions on diethyl phthalate (DEP) concentration in acidic liquids packed in polymeric bottles. HDPE=high-density polyethylene, $\mathrm{PET}=$ polyethylene terephtalate 
HDPE
a) $t=4{ }^{\circ} \mathrm{C}$

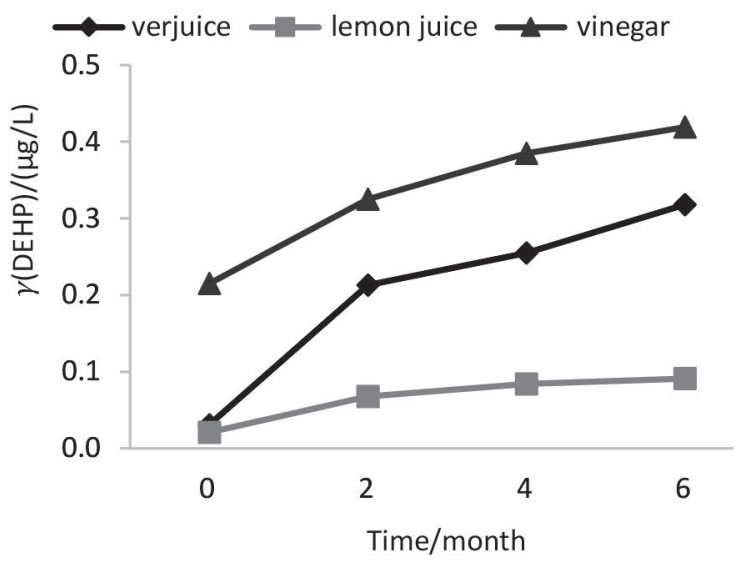

b) $t=25^{\circ} \mathrm{C}$
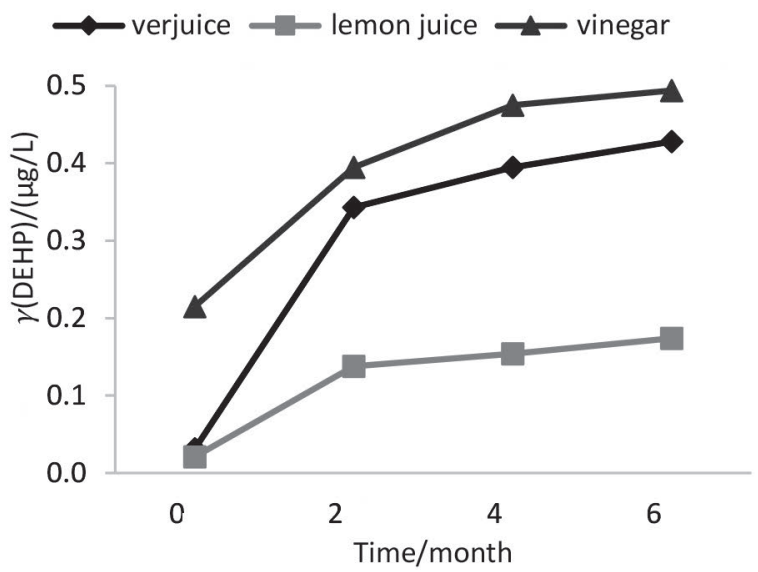

c) $t=50^{\circ} \mathrm{C}$

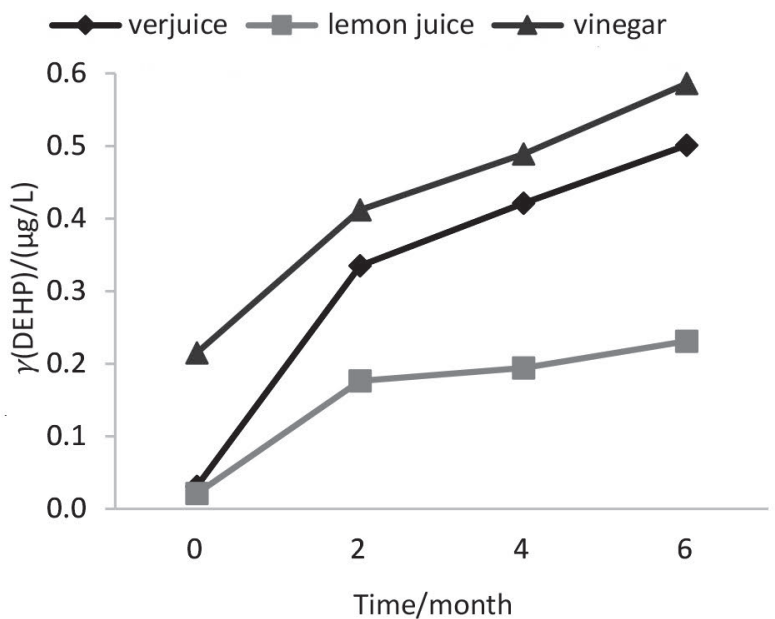

PET

d) $t=4^{\circ} \mathrm{C}$

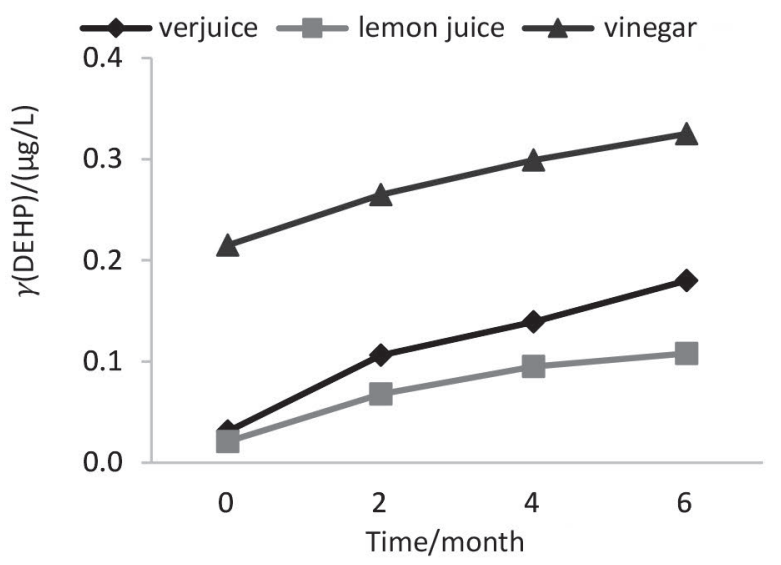

e) $t=25^{\circ} \mathrm{C}$

$\longrightarrow$ verjuice $\longrightarrow$ lemon juice $\longrightarrow$ vinegar

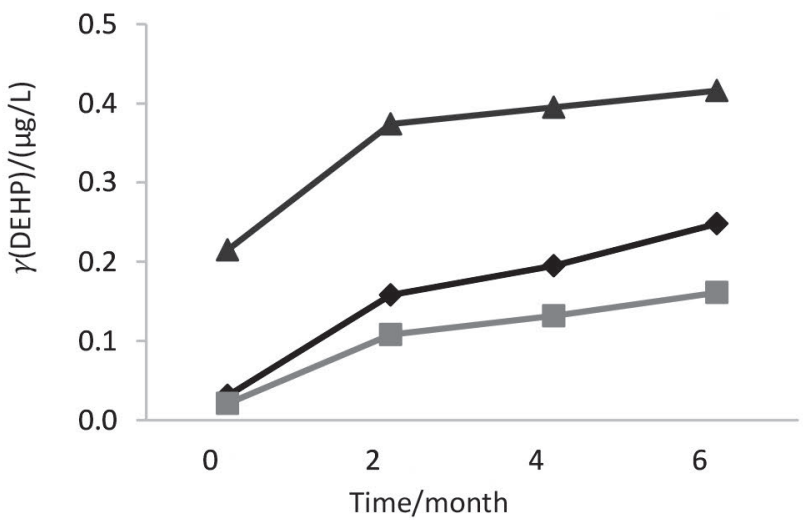

f) $t=50{ }^{\circ} \mathrm{C}$

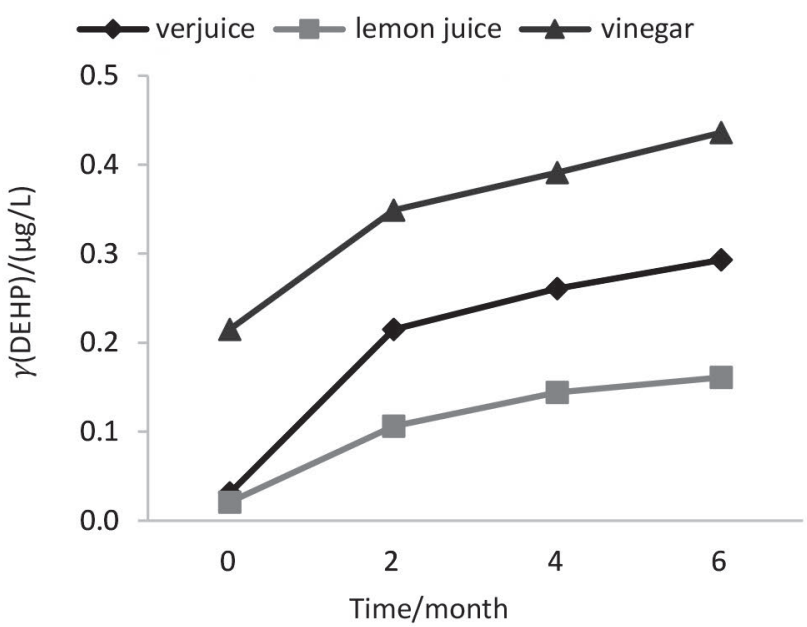

Fig. 2. The effect of time (0, 2, 4 and 6 months) under different storage conditions on bis(2-ethylhexyl) phthalate (DEHP) concentration in acidic liquids packed in polymeric bottles. HDPE=high-density polyethylene, $\mathrm{PET}=$ polyethylene terephtalate 
HDPE

a) $t=4{ }^{\circ} \mathrm{C}$

$\longrightarrow$ verjuice $\longrightarrow$ lemon juice $\longrightarrow$ vinegar

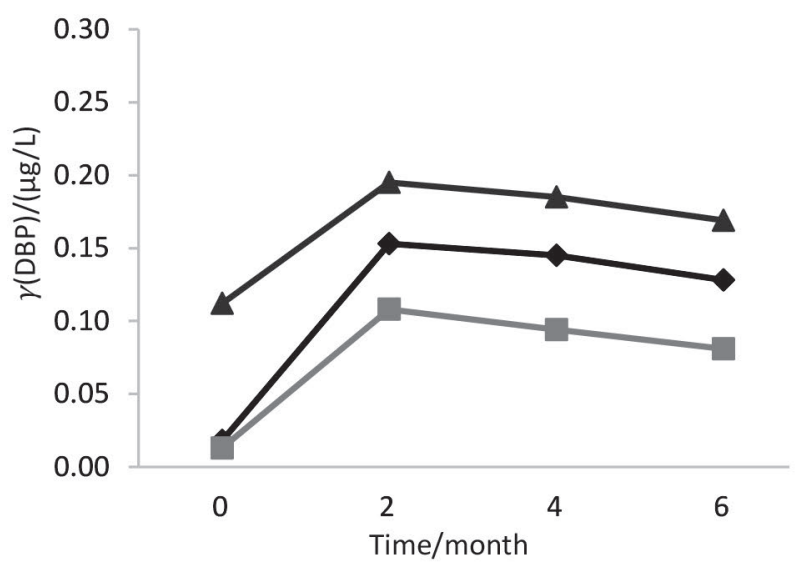

b) $t=25^{\circ} \mathrm{C}$

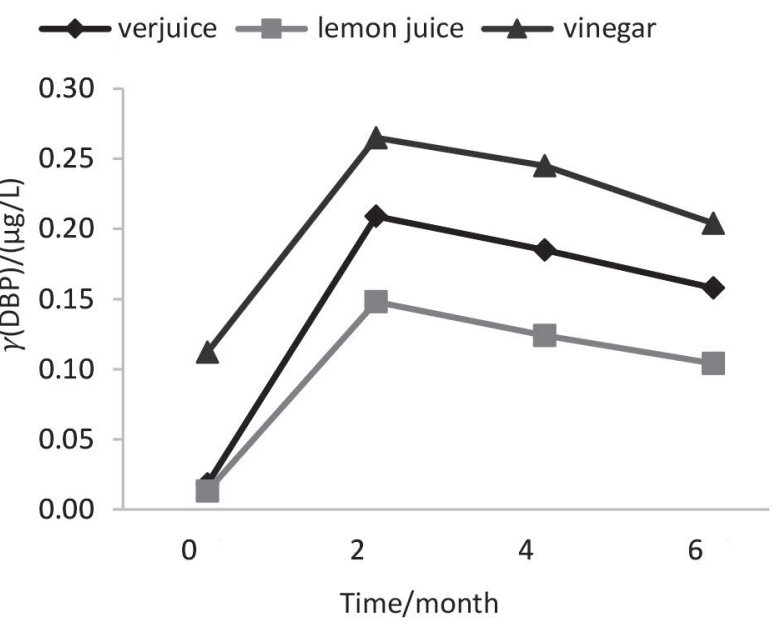

c) $t=50^{\circ} \mathrm{C}$

$\longrightarrow$ verjuice $\longrightarrow$ lemon juice $\longrightarrow$ vinegar

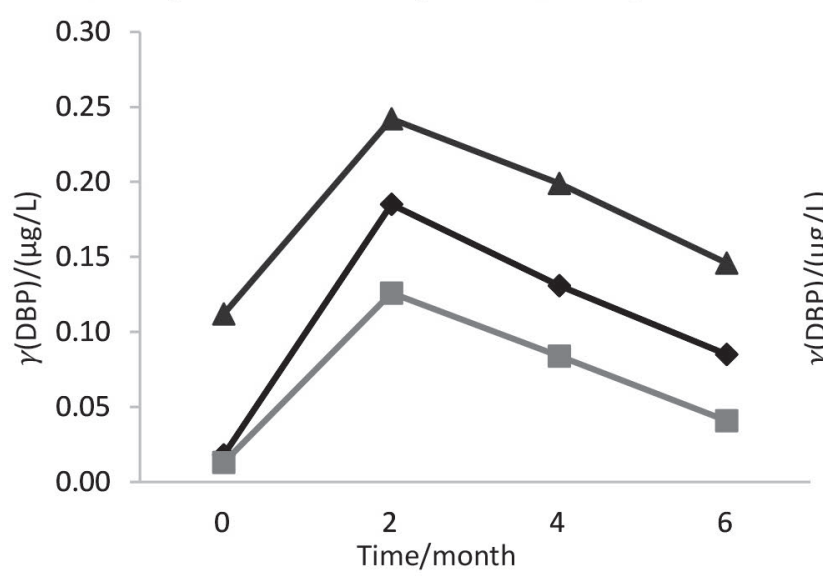

PET

d) $t=4{ }^{\circ} \mathrm{C}$

$\rightarrow$ verjuice $\longrightarrow$ lemon juice $\rightarrow-$ vinegar

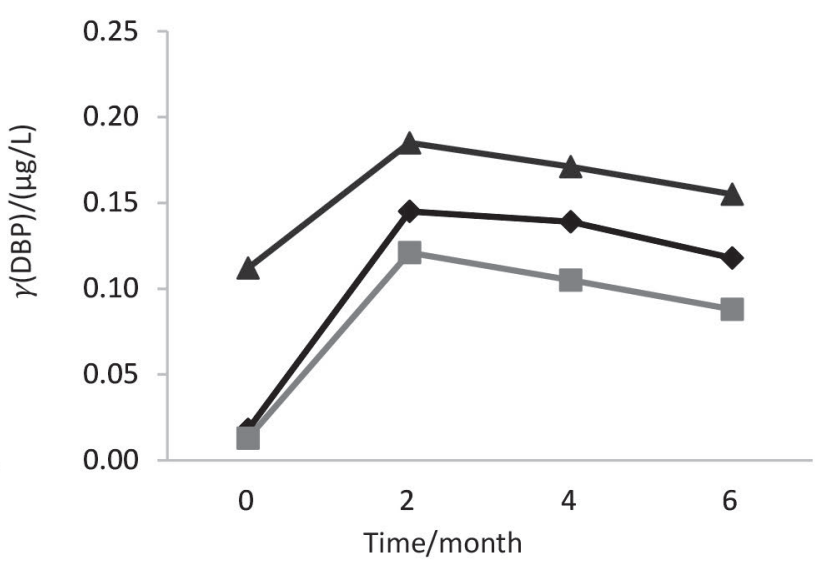

e) $t=25^{\circ} \mathrm{C}$

$\longrightarrow$ verjuice $\longrightarrow$ lemon juice $\longrightarrow$ vinegar

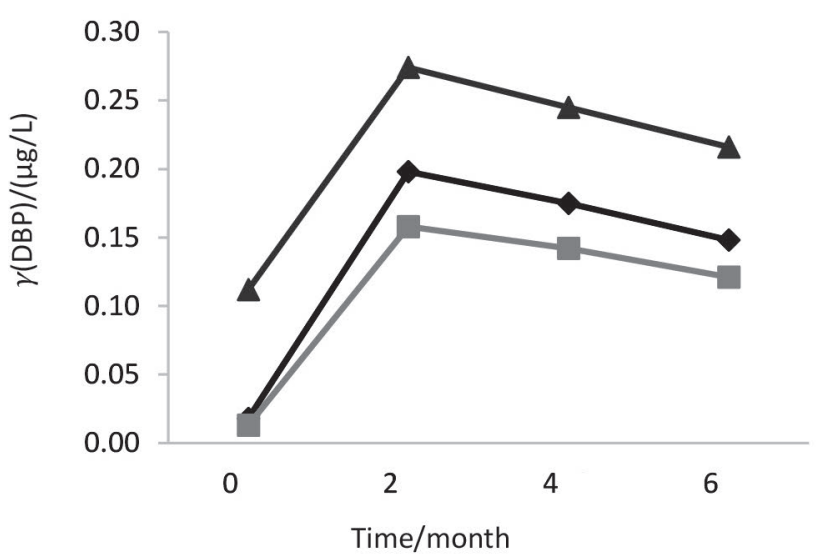

f) $t=50^{\circ} \mathrm{C}$

$\longrightarrow$ verjuice $\longrightarrow$ lemon juice $\longrightarrow$ vinegar

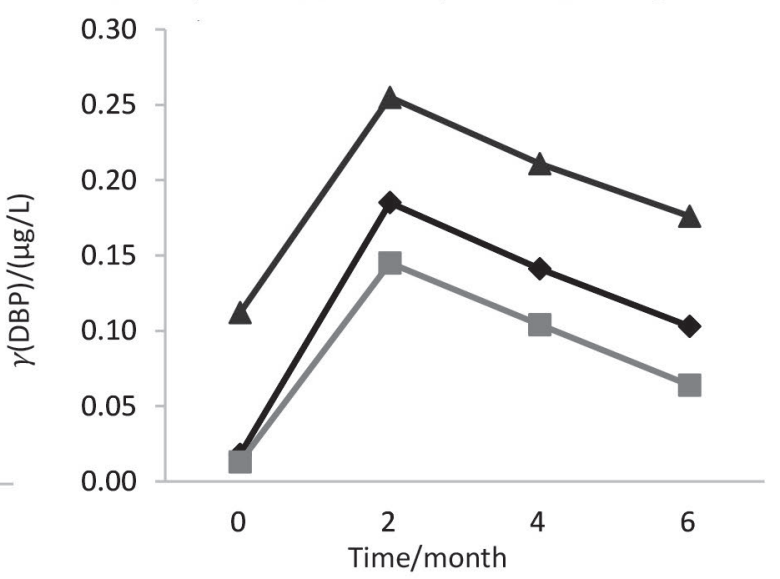

Fig. 3. The effect of time (0, 2, 4 and 6 months) under different storage conditions on dibutyl phthalate (DBP) concentration in acidic liquids packed in polymeric bottles. HDPE=high-density polyethylene, PET=polyethylene terephtalate 
and kept at $50{ }^{\circ} \mathrm{C}$ for 6 months. The effect of storage time $(2,4$ and 6 months) under different conditions is shown in Figs. 1-3. The migration of the phthalates was in the order DEHP $>$ DEP $>$ DBP and DEP $>$ DEHP $>$ DBP in HDPE and PET bottles, respectively. Therefore, DBP migration was the lowest in both kinds of bottles. Based on the results, in addition to the duration of exposure and temperature, the type of liquids in the container affected phthalate migration. Statistical analysis showed a significant difference between lemon juice and the other two liquids. The lowest levels of phthalates were found in lemon juice.

The presence of phthalates in vinegar samples after production can be ascribed to usage of polymeric equipment, including tubing and funnels during vinegar production; nevertheless, the concentration of phthalates in the vinegar samples was increased after 6 months of storage under different conditions, which confirms leaching from the bottle. The significant effect of unsuitable storage conditions on the increase of the concentrations of DEP, DBP and DEHP in the bottled liquids was determined by analysis of the values before and after storage. Our results are similar to previous studies where the concentrations of phthalates in the lemon juice and vinegar samples in PET bottles were found up to $0.44 \mu \mathrm{g} / \mathrm{L}(22)$. Higher concentrations of phthalates up to $140 \mu \mathrm{g} / \mathrm{L}$ were detected in lemon juice and vinegar samples kept in plastic bottles (23). In previous studies $(22,23)$, selected samples were the commercial ones and purchased from public market. Therefore, the initial concentrations of phthalates in the samples were not determined before storage. In this type of sampling, the effect of influencing factors such as previous poor storage conditions and exposure to environmental factors (e.g. sunlight, high temperature, etc.) cannot be excluded. Therefore, the reason for the existence of phthalates in the liquids cannot be described with certainty. On the other hand, the experimental design of the present study led to the conclusion that leaching from the polymeric materials under different storage conditions was the main reason for the increase of the phthalate concentrations.

Analysis of the DEHP concentration results in the differently stored samples indicated that the rate of migration increased with the increase of temperature, but as mentioned above, some reduction of DEP and DBP concentrations can be seen at $50{ }^{\circ} \mathrm{C}$. These results are similar to the results of the abiotic degradation tests of the phthalates (19). The results of previous studies showed that hydrolysis is one of the main factors that control phthalate concentrations in acidic and basic solutions. Degradation of phthalates usually proceeds slowly, but the rate of degradation increases by increasing the temperature. Lau et al. (24) reported that the rates of DEP and DBP degradation were higher at both limits of $\mathrm{pH}$ range, i.e. $\geq 10$ and $\leq 3$. DEP and DBP are usually degraded more than $20 \%$ by hydrolysis under acidic and high temperature conditions (25). However, in the case of DEHP, the effect of hydrolysis is negligible due to spatial crowding around hydrolysis site. In spite of migration of phthalate esters from packaging materials, phthalate concentrations were not considerable in the samples. The highest level of DEHP was found below the maximum allowable contaminant level in drinking water established by the US Environmental Protection Agency, which is $6 \mu \mathrm{g} / \mathrm{L}$ (26).

\section{Conclusions}

In the present study, three factors that were suspected to affect the concentration of phthalates found in bottled liquids including the type of packaging materials, period of storage (duration of contact with packaging materials) and storage temperature were investigated to evaluate their effect on the release of phthalates into the package content. The results indicated that the concentration of phthalates found in bottled liquids depends on all these factors. However, in the samples, phthalate migrations were not considerable. Therefore, the main conclusions are that PET- and HDPE- bottled liquids do not represent a relevant ingestion source of phthalate esters for those who consume these types of packed liquids and therefore, the concentrations of phthalates observed in them are not a matter of concern from the standpoint of adverse health effects.

\section{Acknowledgements}

This research was supported by Tehran University of Medical Sciences grant (project no. 92-01-46-21405). Hereby, the cooperation of the University and also the Institute for Environmental Research (IER) is highly appreciated.

\section{References}

1. Zhang $\mathrm{H}$, Wen $\mathrm{ZG}$. The consumption and recycling collection system of PET bottles: A case study of Beijing, China. Waste Manage. 2014;34:987-98.

https://doi.org/10.1016/j.wasman.2013.07.015

2. Mihucz VG, Záray G. Occurrence of antimony and phthalate esters in polyethylene terephthalate bottled drinking water. Appl Spectros Rev. 2016;51:183-209. https://doi.org/10.1080/05704928.2015.1105243

3. Howdeshell KL, Peterman PH, Judy BM, Taylor JA, Orazio CE, Ruhlen RL, et al. Bisphenol A is released from used polycarbonate animal cages into water at room temperature. Environ Health Persp. 2003;111:1180-7.

4. Bošnir J, Puntarić D, Galić A, Škes I, Dijanić T, Klarić M, et al. Migration of phthalates from plastic containers into soft drinks and mineral water. Food Technol Biotechnol. 2007;45:91-5.

5. Rastkari N, Ahmadkhaniha R, Yunesian M, Baleh LJ, Mesdaghinia A. Sensitive determination of bisphenol A and bisphenol $\mathrm{F}$ in canned food using a solid-phase microextraction fibre coated with single-walled carbon nanotubes before GC/MS. Food Addit Contam. 2010;27:1460-8. https://doi.org/10.1080/19440049.2010.495730

6. Rastkari N, Yunesian M, Ahmadkhaniha R. Levels of bisphenol $\mathrm{A}$ and bisphenol $\mathrm{F}$ in canned foods in Iranian markets. Iran J Environ Health Sci Eng. 2011;8:95-100.

7. Ahmadkhaniha R, Salimi M, Rastkari N. Comparison of single-walled carbon nanotubes, multi-walled carbon nanotubes and C18 as adsorbents for the solid phase extraction of bisphenol A and bisphenol $F$ in canned food. Fullere Nanotub Car N. 2013;21:604-16. https://doi.org/10.1080/1536382X.2011.643430

8. Sax L. Polyethylene terephthalate may yield endocrine disruptors. Environ Health Persp. 2010;118:445-8. https://doi.org/10.1289/ehp.0901253

9. Bach C, Dauchy X, Chagnon MC, Etienne S. Chemical compounds and toxicological assessments of drinking water stored in polyethylene terephthalate (PET) bottles: A source of controversy reviewed. Water Res. 2012;46:571-83. https://doi.org/10.1016/j.watres.2011.11.062

10. Muncke J. Endocrine disrupting chemicals and other substances of concern in food contact materials: An updated review of ex- 
posure, effect and risk assessment. J Steroid Biochem Mol Biol. 2011;127:118-27.

https://doi.org/10.1016/j.jsbmb.2010.10.004

11. Ceretti E, Zani C, Zerbini I, Guzzella L, Scaglia M, Berna V, et al. Comparative assessment of genotoxicity of mineral water packed in polyethylene terephthalate (PET) and glass bottles. Water Res. 2010;44:1462-70. https://doi.org/10.1016/j.watres.2009.10.030

12. Gupta RK, Singh JM, Leslie TC, Meachum S, Flaws JA, Yao HH. Di-(2-ethylhexyl) phthalate and mono-(2-ethylhexyl) phthalate inhibit growth and reduce estradiol levels of antral follicles in vitro. Toxicol Appl Pharmacol. 2010;242:224-30. https://doi.org/10.1016/j.taap.2009.10.011

13. Ghisari M, Bonefeld-Jorgensen EC. Effects of plasticizers and their mixtures on estrogen receptor and thyroid hormone functions. Toxicol Lett. 2009;189:67-77. https://doi.org/10.1016/j.toxlet.2009.05.004

14. Zarean M, Keikha M, Poursafa P, Khalighinejad P, Amin M, Kelishadi R. A systematic review on the adverse health effects of di-2-ethylhexyl phthalate. Environ Sci Pollut Res. 2016;23:2464293. https://doi.org/10.1007/s11356-016-7648-3

15. Chopra V, Harley K, Lahiff M, Eskenazi B. Association between phthalates and attention deficit disorder and learning disability in U.S. children, 6-15 years. Environ Res. 2014;128:64-9. https://doi.org/10.1016/j.envres.2013.10.004

16. Ventrice P, Ventrice D, Russo E, De Sarro G. Phthalates: European regulation, chemistry, pharmacokinetic and related toxicity. Environ Toxicol Pharmacol. 2013;36:88-96. https://doi.org/10.1016/j.etap.2013.03.014

17. Marsh K, Bugusu B. Food packaging - Roles, materials, and environmental issues. J Food Sci. 2007;72:R39-55. https://doi.org/10.1111/j.1750-3841.2007.00301.x

18. Cirillo T, Fasano E, Esposito F, Del Prete E, Cocchieri RA. Study on the influence of temperature, storage time and packaging type on di-n-butylphthalate and di(2-ethylhexyl)phthalate re- lease into packed meals. Food Addit Contam A. 2013;30:403-11. https://doi.org/10.1080/19440049.2012.745198

19. Lertsirisopon R, Soda S, Sei K, Ike M. Abiotic degradation of four phthalic acid esters in aqueous phase under natural sunlight irradiation. J Environ Sci. 2009;21:285-90. https://doi.org/10.1016/S1001-0742(08)62265-2

20. Jeddi MZ, Ahmadkhaniha R, Yunesian M, Rastkari N. Magnetic solid-phase extraction based on modified magnetic nanoparticles for the determination of phthalate diesters in water samples. J Chromatogr Sci. 2015;53:385-91. https://doi.org/10.1093/chromsci/bmu058

21. IBM SPSS Statistics for Windows, v. 20.0, IBM Corp. Armonk, NY, USA; 2011.

22. Yılmaz PK, Ertaş A, Kolak U. Simultaneous determination of seven phthalic acid esters in beverages using ultrasound and vortex-assisted dispersive liquid-liquid microextraction followed by high-performance liquid chromatography. J Sep Sci. 2014;37:2111-7. https://doi.org/10.1002/jssc.201400408

23. Farajzadeh MA, Khoshmaram L. Development of dispersive liquid-liquid microextraction technique using ternary solvents mixture followed by heating for the rapid and sensitive analysis of phthalate esters and di(2-ethylhexyl) adipate. J Chrom A. 2015;1379:24-33. https://doi.org/10.1016/j.chroma.2014.12.049

24. Lau TK, Chu W, Graham N. The degradation of endocrine disruptor di-n-butyl phthalate by UV irradiation: A photolysis and product study. Chemosphere. 2005;60:1045-53. https://doi.org/10.1016/j.chemosphere.2005.01.022

25. Keresztes S, Tatár E, Czégény Z, Záray G, Mihucz VG. Study on the leaching of phthalates from polyethylene terephthalate bottles into mineral water. Sci Total Environ. 2013;458-460:451-8. https://doi.org/10.1016/j.scitotenv.2013.04.056

26. Al-Saleh I, Shinwari N, Alsabbaheen A. Phthalates residues in plastic bottled waters. J Toxicol Sci. 2011;36:469-78. https://doi.org/10.2131/jts.36.469 